\title{
Repeat RF Ablation of C2 and Third Occipital Nerves for Recurrent Occipital Neuralgia and Cervicogenic Headaches
}

\author{
John F. Hamer'1, Traci A. Purath ${ }^{2}$ \\ ${ }^{1}$ Oak Brook, IL, USA \\ ${ }^{2}$ Purath Headache and Neurology, Greenfield, WI, USA \\ Email: filatovaev@img.ras.ru
}

How to cite this paper: Hamer, J.F. and Purath, T.A. (2016) Repeat RF Ablation of C2 and Third Occipital Nerves for Recurrent Occipital Neuralgia and Cervicogenic Headaches. World Journal of Neuroscience, 6, 236-242.

http://dx.doi.org/10.4236/wjns.2016.64029

Received: August 30, 2016

Accepted: October 16, 2016

Published: October 19, 2016

Copyright $\odot 2016$ by authors and Scientific Research Publishing Inc. This work is licensed under the Creative Commons Attribution International License (CC BY 4.0).

http://creativecommons.org/licenses/by/4.0/

\begin{abstract}
Objective: To address the degree and duration of pain relief from recurrent cervicogenic headaches and/or occipital neuralgia following retreatment with radiofrequency ablation of the $\mathrm{C} 2$ dorsal root ganglion and/or third occipital nerves; to review outcomes including duration and degree of pain relief; to evaluate procedure's complication rate and patient's willingness to repeat the procedure; to compare effectiveness of the most recent RF ablation to patient's first RF ablation. Methods: This is a single-center retrospective observational study of 23 patients with recurrent cervicogenic headaches and/or occipital neuralgia treated with repeated RF ablation of the C2 dorsal root ganglion and/or third occipital nerves. All patients receiving treatment from January 2010 to July 2014 are included in this single site retrospective study. This is an IRB approved medical chart review study. Results: 22 of 23 patients underwent follow-up. An average of $86.5 \%$ of participants reported pain relief on average of 25.4 weeks at time of follow-up. $41 \%$ reported side effects including suboccipital hyperesthesia and/or ear discomfort, $95 \%$ reported willingness to repeat the procedure again if severe symptoms recurred, 59\% of patients reported the most recent $\mathrm{RF}$ ablation had the same results as the first, $32 \%$ reported the most recent $\mathrm{RF}$ was the most effective, and 9\% reported that the first RF was the most effective. Conclusion: Repeated RF ablation is a feasible option for recurrent cervicogenic headaches and/or occipital neuralgia. Effectiveness of repeat intervention is the same or better than the first ablation. Though there was a higher likelihood of side effects including suboccipital neuralgia and/or ear discomfort on repeat treatment, the side effects were generally well tolerated.
\end{abstract}

\section{Keywords}

Occipital Neuralgia, Cervicogenic Headache, Radiofrequency Ablation 


\section{Introduction}

Cervicogenic headaches and occipital neuralgia can be a challenge to diagnose and treat [1]. Even when successfully treated, symptoms can often reoccur, leading to the need to repeat treatment. Despite therapies including RF neurolysis have reported success, there is no published data on the efficacy of retreatment.

Underlying causes can include traumatic causes such as whiplash injury, or degenerative causes include arthropathy of the zygapophyseal joints [2] [3]. Although the likely cause is often speculated based on clinical history of trauma or imaging findings of osteoarthritis, a definitive reason often cannot be proven. If the underlying cause is not corrected, then symptomatic relief is often temporary.

RF neurolysis pain relief is thought to be temporary as there is nerve healing following the injury caused by the RF lesioning. We know from animal models that following nerve RF neurolysis, the nerve undergoes endoneurial edema followed by Wallerian degeneration [4]. Following nerve healing or regrowth symptoms may recur and if severe may need repeated treatment.

\section{Methods}

This report represents a single-center retrospective observational study of 23 patients with recurrent cervicogenic headaches and or occipital neuralgia treated with repeat RF ablation of the $\mathrm{C} 2$ dorsal root ganglion and/or third occipital nerves. All patients receiving treatment from January 2010 to July of 2014 are included in this study. This is an IRB approved medical chart review study.

All patients were referred by headache specialized neurologists from two centers. All eligible candidates underwent detailed neurologic evaluation followed by consultation in our interventional department. After receiving a diagnosis of cervicogenic headaches and/or occipital neuralgia proven with confirmative nerve blocks, patients underwent $\mathrm{RF}$ ablation. Those with recurrent severe symptoms were treated with $\mathrm{RF}$ ablation one or more times over the study period beginning in January 2010 and ending July 2014.

Follow up occurred by telephone at 3 - 4 days, and either in person or by telephone at 6 - 12 months after treatment. Patients were questioned and information was added to medical charts. Following chart review of all candidates in this IRB approved retrospective study, data was entered into an Excel spreadsheet. All treated patients were included except those for whom long-term follow up was not available. All 23 patients underwent repeat treatment. 22 of the 23 patients participated in long term follow up for a minimum of 2 months. One patient did not return phone calls and was excluded from the study.

Patients were questioned as to how long in weeks or months the most recent RF ablation provided them significant pain relief. They were asked what percentage relief was provided, with $100 \%$ pain relief meaning no headaches and able to participate in all usual activities. $0 \%$ pain relief providing no benefit with severe headaches limiting participation in their usual activities. They were asked to compare the last RF treatment with the first they had received with either the first being overall better, the last being 
better, or both providing the same degree of relief. Inquiry as to any therapy side effects was asked, specifically if they had any scalp hyperesthesia. Each was questioned as to any other medical headache treatment they attempted during that time if any and if they would recommend RF ablation to friends and family or have it again if severe symptoms recur.

\section{Procedure}

All patients were positioned in a lateral decubitus position painful side up. Conscious sedation was provided. All RF ablations were performed by a single fellowship trained neuroradiologist under fluoroscopic guidance. RF ablation performed using a Stryker International Spine RF Multigenerator (Synergetics USA, Inc., O'Fallon, MO, USA) and Stryker $100 \mathrm{~mm}$ RF cannula with $10 \mathrm{~mm}$ active tip and $50 \mathrm{~mm}$ RF cannula with 5 $\mathrm{mm}$ active tip. At the level of $\mathrm{C} 2$ dorsal root ganglion RF ablation, 1 or two RF needles were placed using a direct lateral transforaminal approach paralleling the $\mathrm{C} 2$ dorsal root ganglia. At the level of the third occipital nerve (TON) two or three needles were placed using a posterior lateral and or direct lateral median branch approach paralleling the TON as it courses around the articular pillar of the C2-C3 facet joint. Sensory testing at $50 \mathrm{~Hz}$ and motor testing at $2.0 \mathrm{~Hz}$ was performed before the ablation. RF ablation was then carried out at $80^{\circ}$ Celsius for 90 seconds, when well tolerated this was repeated after rotating RF needle 180 degrees and repeating sensory and motor testing.

Patient periprocedural pain generally treated with oxycodone or hydrocodone with acetaminophen for 2 - 3 days as needed. Follow up occurred 2 hours after treatment in person by proceduralist, 3 - 4 days after treatment by interventional radiologist nurse by telephone, or by telephone or in person at 2 months to 1 year after last RF procedure.

\section{Results}

Analysis was performed using data entered in a Microsoft@ Excel spreadsheet (Microsoft, Redmond, WA, USA).

Twenty-two of 23 patients underwent follow-up. One of the 23 could not be reached after the second RF ablation and was therefore not included in the final study results. See Table 1 for summary of patient data.

There is an average of $86.5 \%$ pain relief at time of follow-up. Six of the twenty-two or $27 \%$ reported $100 \%$ pain relief at time of follow-up. Sixteen of the 22 or $72 \%$ reported $80 \%$ or greater pain relief. Two of 22 or $9 \%$ reported $50 \%$ or less pain relief. One of those patients reported $50 \%$ pain relief the other $40 \%$.

Average duration of pain relief was 25.4 weeks or 6.35 months. The longest period of relief at time of follow up was 56 weeks with no return of headaches and $100 \%$ improvement from time of RF ablation. Fifteen of the 22 or $68 \%$ had 6 months or more of improvement. Eight of 22 or $36 \%$ reported less than 6 months of pain relief, however, five were still experiencing a high degree of pain relief with no significant return of symptoms at the time of follow up. For details on duration of pain relief (see Figure 1). 
Table 1. Demonstrates summary of follow-up data regarding RF ablation pain relief, side effects and other attempted treatments.

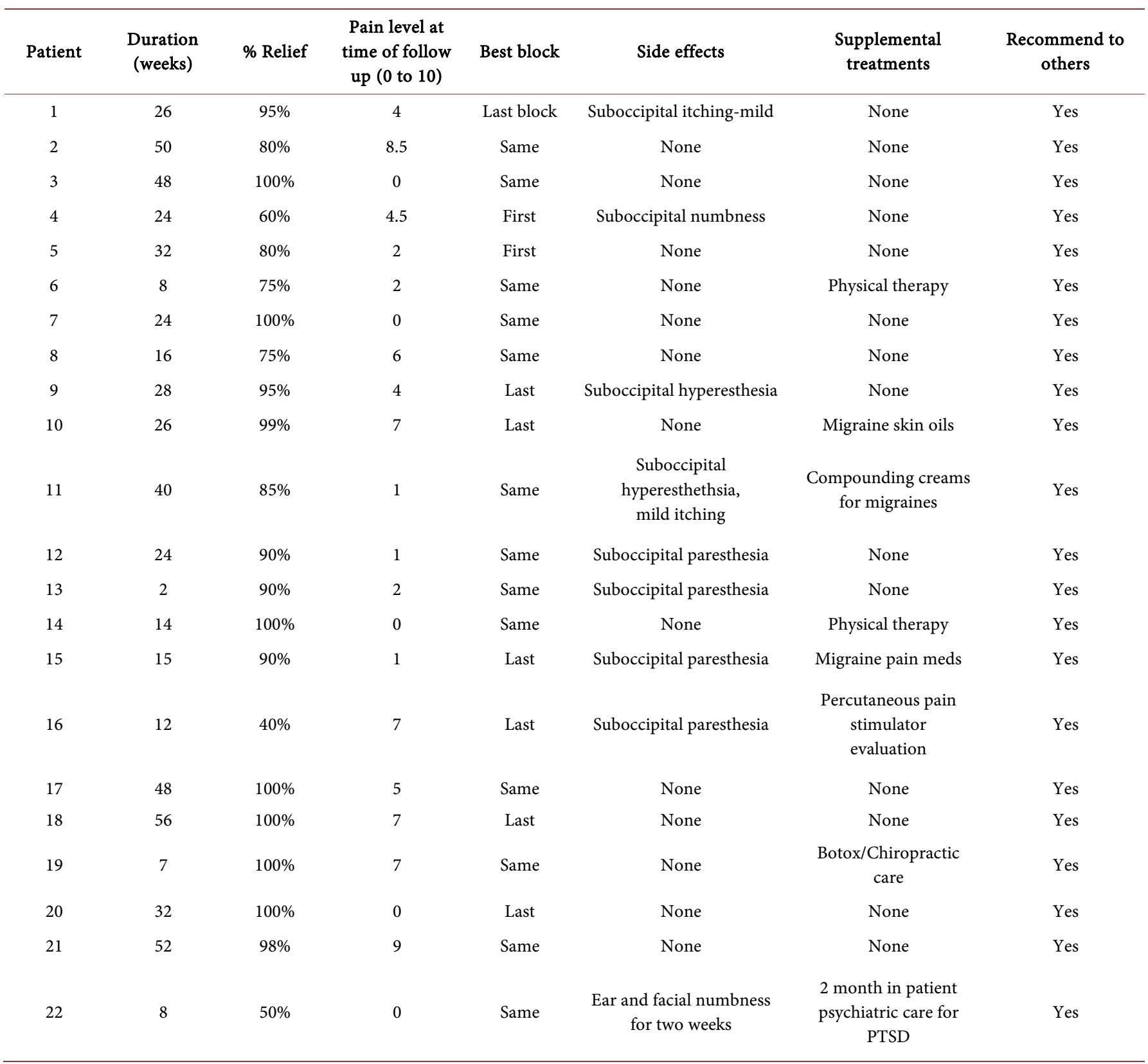

Average reported pain at time of last follow up was 2.9 on a scale of 0 to 10 with 10 being the most severe pain imaginable and 0 being no pain. Zero pain reported in 7 of 22 or $32 \%$. Thirteen of 22 or $59 \%$ reported pain level of 2 or less at time of last follow up. One of 22 or $5 \%$ reported pain at time of follow-up for $8-10$. Four of 22 or $18 \%$ reported headaches at times reaching a level of up to 8 or greater at times but not at the time of follow up. One of those stated the headaches were severe $8-10$ but very rare compared to pre-treatment frequency of headache pain.

Complications and or side effects occurred in 9 of 22 or $41 \%$. Reported side effects included suboccipital hyperesthesia, scalp itching, or ear discomfort. None of the side 
effects were considered more than mild. The most common side effects were suboccipital numbness or paresthesia in 5 of 22 or $23 \%$, and suboccipital itching in two of 22 or 9\%. One patient, 5\% experienced ear and facial numbness for duration of 2 weeks. Thirteen of 22 or $57 \%$ reported no side effects or complications. See Figure 2 a graph of side effects and/or complications.

Twenty-one of 22 patients or $95 \%$ would have it again or recommend it to others with severe symptoms. One patient would not as her chronic headaches were later diagnosed as being related to post-traumatic stress disorder related to a childhood event. After a two month stay in a specialty psychiatric clinic her chronic headaches resolved completely and had not returned as of time of last follow-up.

Fifty-nine percent of patients reported the most recent RF ablation had same results as the first, $32 \%$ reported the most recent RF was the most effective, and $9 \%$ that the first RF was the most effective.

Eleven of 22 or $50 \%$ did not seek any other medical care during the time after RF treatment by time of follow up, $50 \%$ did. Five of the 22 sought treatment of coexisting Migraine headaches including two patients Botox, migraine related oral pain med or compound creams, online purchases migraine skin oils, one patient each. One of the patients that sought Botox for migraines also saw chiropractor. Two patients sought

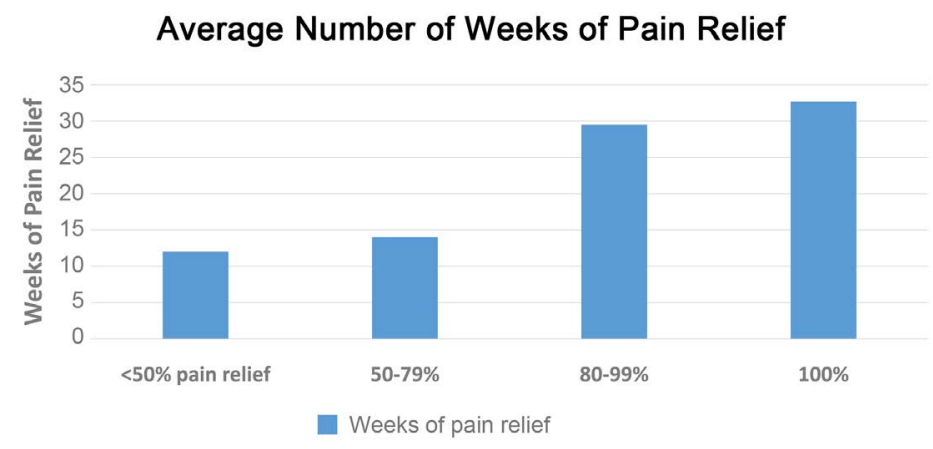

Figure 1. Average duration of pain relief for patients with different percent pain relief.

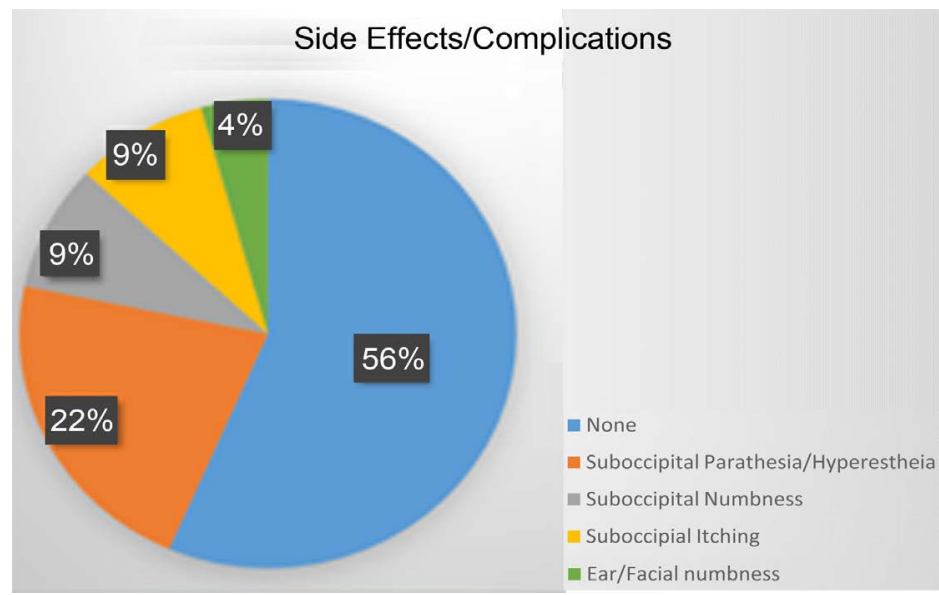

Figure 2. Graph of side effects/complications. 
physical therapy, one of who was $100 \%$ pain free for preventative care. One patient who experienced the return of severe pain underwent anesthesia consult for spine pain stimulator.

\section{Discussion}

$\mathrm{RF}$ ablation is an aggressive treatment that should be reserved for patients that have exhausted conservative treatments including physical therapy. If the first RF ablation was successful and severe symptoms recur, then repeat treatment is a very reasonable consideration.

The average duration of pain relief is underestimated due to the inherent methodology of this retrospective study. For example, one patient had follow up 2 weeks after last treatment, time of data collection for all patients, their pain relief is recorded as only 2 weeks as we do not know their actual length of pain relief. This could be adjusted for by either eliminating patients that do not to have a minimum of 6 months of follow up after last procedure but due to interest in increasing study cohort size this limitation was accepted.

The average result was $86.5 \%$ for 25.4 weeks. As this patient population has a lack of other accessible alternative treatments, this length and percentage of pain reduction is reasonable. Alternatives would include decompressive rhizotomy by neurosurgeon, suboccipital rhizotomy by plastic surgeon, or pain stimulator placement. None of the patient in this cohort had any of the above treatments, they were all consulted of these alternative and several sought consultations by surgeons and chronic pain practitioners.

Repeat success is similar to first treatment in a general sense, actual data to support this was not collected in this study. Previous published data including part of the same subset of patients demonstrated $78.1 \%$ of 22.3 weeks of pain relief [5]. The slightly improved results are likely in part due to selection bias compared to the group treated for the first time as patients with less degree or length of pain improvement would be less likely to repeat the procedure.

Inherent retrospective nature of this study with one treating proceduralist is a limitation. There is also lack of documented standardization of treatment between first and last RF ablations with a general tendency to be more aggressive on subsequent treatments by burning a larger area. Several of these patients also underwent more than two procedures but only the first and last are included.

Complication rate is higher compared to previous published results. The complication rate although higher included no complications that were considered more than mild and all patients with side effects and or complications reported satisfaction with the procedure and would recommend it to others.

Further research is needed to determine if there is long-term sequela of numerous RF ablations, particularly if patients undergo 3 or more ablations. A prospective study with control group would be helpful.

\section{Conclusion}

Repeated RF ablation is a feasible option for recurrent cervicogenic headaches and/or 
occipital neuralgia. Effectiveness is the same or better than the first ablation, and high likelihood of side effects include suboccipital neuralgia and/or ear discomfort, although side effects are generally well tolerated.

\section{References}

[1] Biondi, D.M. (2005) Cervicogenic Headache: A Review of Diagnostic and Treatment Strategies. The Journal of the American Osteopathic Association, 105, 16S-22S.

[2] Lord, S.M., Barnsley, L., Wallis, B.J., McDonald, O.J. and Bogduk, N. (1996) Percutaneous Radio-Frequency Neurotomy for Chronic Cervical Zygapophyseal-Joint Pain. The New England Journal of Medicine, 335, 1721-1726. http://dx.doi.org/10.1056/NEJM199612053352302

[3] Vittal, R.N., Pravardhan, B., Jay, G.S. and Amit, A. (2015) Systematic Review of Radiofrequency Ablation and Pulse Radiofrequency for Management of Cervicogenic Headache. Pain Physician, 18, 109-130.

[4] Podhajsky, R.J., Sekiguchi, Y., Kikuchi, S. and Myers, R. (2005) The Histologic Effects of Pulsed and Continuous Radiofrequency Lesions at $42^{\circ} \mathrm{C}$ to Rat Dorsal Root Ganglion and Sciatic Nerve. Spine, 30, 1008-1013. http://dx.doi.org/10.1097/01.brs.0000161005.31398.58

[5] Hamer, J. and Purath, T. (2014) Response of Cervicogenic Headaches and Occipital Neuralgia to Radiofrequency Ablation of the Dorsal Root Ganglion and/or Third Occipital Nerve. Headache, 335, 500-510. http://dx.doi.org/10.1111/head.12295

Submit or recommend next manuscript to SCIRP and we will provide best service for you:

Accepting pre-submission inquiries through Email, Facebook, LinkedIn, Twitter, etc.

A wide selection of journals (inclusive of 9 subjects, more than 200 journals)

Providing 24-hour high-quality service

User-friendly online submission system

Fair and swift peer-review system

Efficient typesetting and proofreading procedure

Display of the result of downloads and visits, as well as the number of cited articles

Maximum dissemination of your research work

Submit your manuscript at: http://papersubmission.scirp.org/

Or contact wjns@scirp.org 